\title{
BIBLIOTECA DO COLÉGIO ESTADUAL MANOEL VILAVERDE: UM ESPAÇO ALÉM DAS QUATRO PAREDES
}

\section{Maria Aparecida Rodrigues de Souza}

\section{Resumo}

Relato de experiência da prestação de serviços e atividades de leitura desenvolvidas na Biblioteca Domingos Garcia Filho do Colégio Estadual Manoel Vilaverde, em Inhumas - Goiás. Este relato faz um apanhado das estratégias para estímulo à leitura praticadas pela BDGF desde a sua reativação em 2001; ano em que o colégio foi contemplado com mais de 1300 livros pelo Programa de Bibliotecas das Escolas Estaduais do Estado de Goiás. Ilustramos através de fotos a participação efetiva dos alunos nos projetos desenvolvidos pela biblioteca. Durante o período de 2001 a 2004 foram desenvolvidos dois grandes projetos: Minutos de Leitura e o Projeto Pró-melhoria dos recursos pedagógicos do CEM. Projetos estes que envolvem diretamente a biblioteca, responsável pela mediação do usuário com a leitura e a pesquisa.

\section{Palavras -Chave}

Biblioteca escolar; Projetos de leitura; Pesquisa escolar.

\section{STATE SCHOOL MANOEL VILAVERDE LIBRARY: A SPACE BEYOND FOUR WALLS}

\begin{abstract}
It reports experience in service and reading activities developed in the Library Domingos Garcia Filho of the State School Manoel Vilaverde, in Inhumas - Goias. This report summarizes strategies developed to encourage reading since the library in 2001 was reopened, in this year the school was given with more than 1300 books by the Program of Library of the State Schools of Goias. We demonstraded by means of photos the participation of them in the projects developed by the library. During the period from 2001 to 2004 were developed two great projects: "Minutos de Leitura e o Projeto Pró-melhoria dos recursos pedagógicos do CEM”. These projects involve directly the library, institutions in charge of the interface among user, reading and the research.
\end{abstract}

Key-Words

School library; Lecture projects; School search. 


\section{INTRODUÇÃO}

O Colégio Estadual Manoel Vilaverde (CEM), escola de ensino médio, criou em 1977 a Biblioteca Domingos Garcia Filho (BDGF), que desde então vem formando seu acervo através dos programas desenvolvidos pelo Governo Federal e Estadual de incentivo à leitura, e também através de doação da comunidade, Amigos da Escola, além de aquisições feitas através de campanhas. Atende diariamente 650 usuários (corpo docente, discente e administrativo, é aberto também à comunidade em geral).

Nos últimos quatro anos a BDGF vem crescendo e demonstrando sua importância no cenário escolar. Desde sua reestruturação em 2001, cada vez mais usuários buscam a BDGF para acessar informações sobre diversos temas, seja para um trabalho escolar ou lazer.

"Penso que a maior contribuição da biblioteca para mim este ano, foi no sentido de me ajudar a escrever melhor e me enriquecer culturalmente. Pois a biblioteca me ofereceu um maior número e variedade de livros, e também qualidade" (Mônica Gama Fileti, 2003).

É assim que Mônica Gama Fileti - aluna destaque em leitura e pesquisa do $3^{\circ}$ ano do ensino médio em 2003 do CEM - define o papel que a BDGF exerceu na sua vida escolar. Sua fala confirma a importância que a biblioteca tem desempenhado na formação de diversos alunos que por ela passam.

Como bacharel em Biblioteconomia desde 1996, pela Universidade Federal de Goiás. Desde o ano de 2001 venho atuando na coordenação da BDGF, preocupando em detectar os anseios e necessidades pedagógicas e informacionais da comunidade escolar (corpo docente, discente e administrativo) para saná-las.

Ainda, no final do ano letivo de 2001 fomos beneficiados pelo Programa de Bibliotecas das Escolas Estaduais (PBEE) com a aquisição de mais de 1300 obras literárias e de apoio. E como a escola já possuía uma proposta de política de leitura, com a chegada de novos livros providenciamos de imediato a transferência do espaço da biblioteca para um local amplo, arejado e bem iluminado. Fomos contemplados também, pelo mesmo 
programa, com um mobiliário novo (mesas com cadeiras e estantes). Essas mudanças contribuíram para a eficácia dos projetos de leitura desenvolvidos pela BDGF e permitiu atrair novos usuários.

Para Martinez e Calvi (1994), a biblioteca escolar é uma porta de acesso a emoções, respostas, soluções e prazer, que dá possibilidade de voar com a imaginação, de criar e ter novas idéias, de solucionar problemas simples e complexos. Para merecer o conceito de biblioteca escolar dados pelas autoras acima, a BDGF passou a desenvolver ações que visassem incentivo à leitura e pesquisa, atualização do acervo e atendimento de qualidade.

A seguir, descreveremos as principais ações de incentivo à leitura pela BDGF.

\section{SERVIÇO DE REFERÊNCIA}

O serviço de referência além de oferecer informações gerais sobre a biblioteca, responde às perguntas sobre eventos promovidos pela escola e comunidade local, inscreve leitores, empresta livros, orienta os usuários quanto à localização de livros e assuntos, agenda e recebe visitas de alunos de outras escolas.

Além disso, o serviço de referência é responsável pelo ambiente agradável, onde as pessoas podem conversar - desde que não atrapalhe o estudo dos demais freqüentadores da biblioteca - discutir problemas, trocar idéias, criar, auto-instruir-se (MARTINEZ; CALVI,1994), tendo contato não só com a cultura através do material bibliográfico, mas também de outras atividades culturais e de lazer como oficinas literárias e apresentações teatrais.

A atuação da BDGF não se restringiu ao seu limite físico. Utilizamos desde a sala de aula ao pátio da escola através de apresentações literárias e jornal, com o intuito de levar a informação ao maior número de usuários. Procuramos desenvolver atividades na biblioteca de forma lúdica, demonstrando as várias formas de leitura, seja escrita, oral e/ou visual. Desenvolvemos atividades tais como: bate-papo com escritor, oficinas de métodos e técnicas de apresentação de trabalhos escolares e concursos literários. 


\section{PROJETOS EM AÇÃO}

A seguir detalharemos os projetos em andamento da BDGF que estimulam a produção de textos, à leitura e pesquisa, principalmente a sintonia entre o triângulo alunoprofessor-biblioteca.

\subsection{Projeto Aprendiz de bibliotecário}

A equipe de trabalho da BDGF é composta por seis pessoas: 01 bibliotecária, 02 auxiliares, 02 bolsistas e 01 aluno monitor. A partir do segundo semestre de 2002 desenvolveu-se o projeto Aprendiz de bibliotecário, trabalho de integração dos alunos à biblioteca. Os alunos além de serem mediadores da leitura na biblioteca, aprendem a manusear os livros, localizar o material solicitado, e atendimento aos usuários, com a supervisão da coordenação da biblioteca e com apoio da direção e coordenação pedagógica. Os alunos ficam empolgados por colaborar, aumentam sua auto-estima, sentem-se importantes, como realmente são, e descobrem o valor do trabalho em grupo e do voluntariado.

\subsection{Projeto Minutos de leitura}

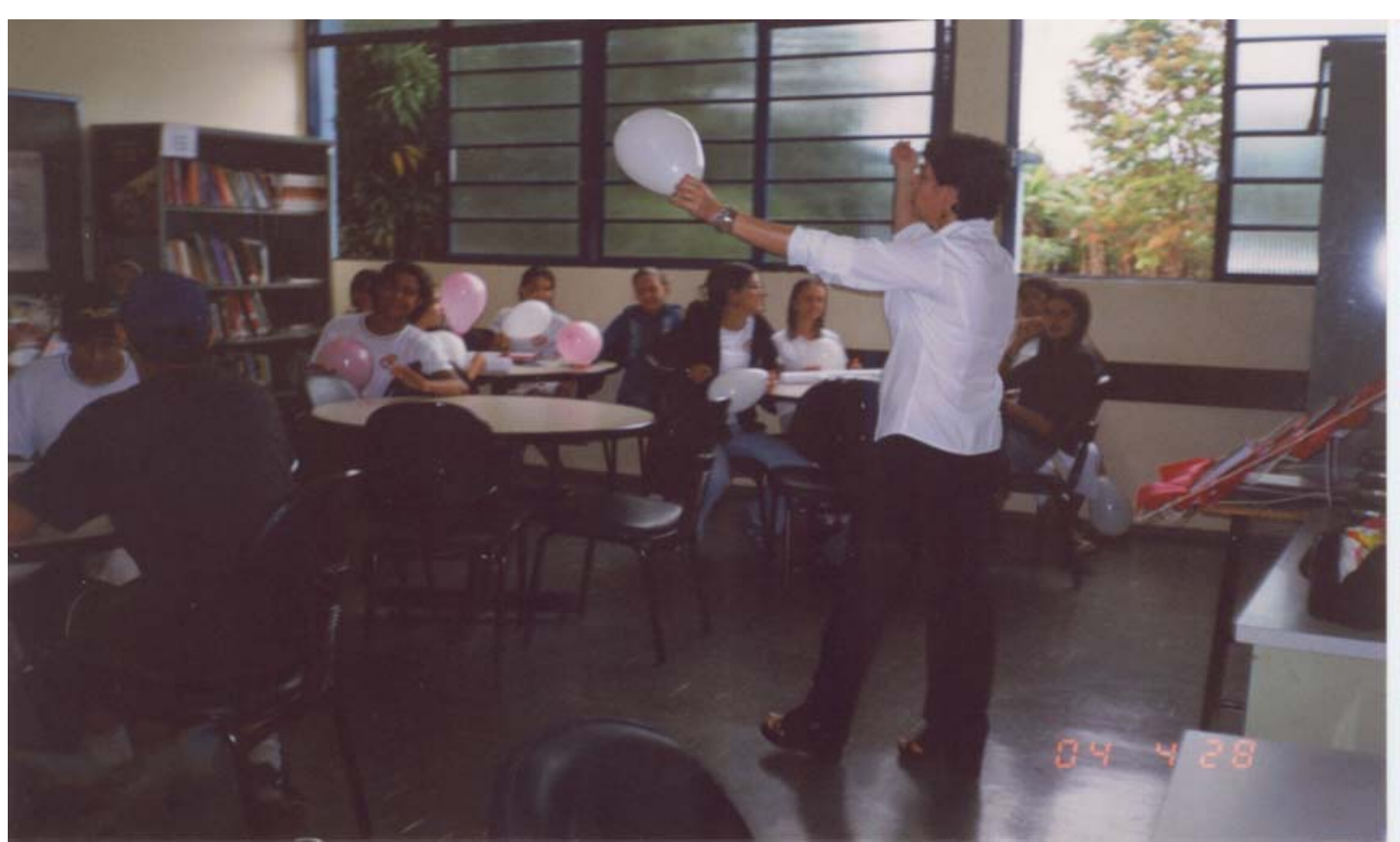

Oficina de cartazes educativos - Dinâmica do Balão (28/04/04) 
O Projeto Minutos de leitura é um momento dedicado à leitura, tendo como públicoalvo os alunos de $1^{\circ} \mathrm{s}$ anos. Criado pela BDGF, o projeto acontece anualmente num clima de muita euforia, interesse e participação de toda a comunidade escolar. O projeto tem como objetivo promover a interdisciplinaridade escolar e, ao mesmo tempo, disseminar a leitura como meio de lazer e cultura.

Em abril de 2002 implantamos o Projeto Minutos de Leitura, que coincidiu com a Campanha Tempo de Leitura do Governo Federal e com o aniversário do escritor Monteiro Lobato. O projeto foi desenvolvido em parceria com os professores de todas as disciplinas. São realizadas as seguintes atividades: bate-papo com escritores inhumenses, sobre sua vida e obras; oficinas literárias; apresentação teatral pelos alunos; recitação de poesia e contação de histórias; painéis de resenhas de livros recomendados por professores e pelos melhores leitores do bimestre. E por fim, minutos de leitura utilizando os livros expostos no galpão e na quadra da escola.

Ao incentivar a melhoria do ensino/aprendizagem com momentos de leituras de boa qualidade, o projeto Minutos de leitura vem proporcionando uma maior integração entre professores, alunos e biblioteca, e principalmente, despertando em nossos jovens, o gosto pela leitura e pela escrita. Diante do sucesso obtido com o projeto, a Direção da escola inseriu o evento no Plano de Desenvolvimento da Escola (PDE) para dar sustentabilidade ao projeto.

Concluindo, pode-se dizer que o colégio vivenciou durante a execução do projeto muitos minutos de encantamento e magia em que a imaginação criou asas e voou para os mundos da cultura e da leitura. Pois ler é um ato que vai além da escrita (MARTINS, 1994, FREIRE, 1994).

\section{Dados quantitativos 2001/2004}

- 08 oficinas de Literatura realizadas, para alunos de $1^{\circ} \mathrm{s}$ anos do ensino médio;

- 1600 alunos beneficiados pelo projeto;

- O número de cadastro da biblioteca passou de 300 inscritos para 800; 
- $\quad 2.200$ títulos adquiridos através de compra e doação beneficiando 1.200 alunos;

- 37 professores beneficiados com obras de apoio.

\section{Atividades}

- Bate-papo com escritores inhumenses - 2002/ 2004

- Apresentação teatral e contação de história pelos alunos, baseadas em obras literárias - 2001/ 2004

- Oficina de cartazes educativos -2004

- Oficina de contação de histórias - 2003/2004

- Exposição de livros indicados pelos professores e alunos - 2002/2004

- Oficina de jornal - 2003/2004

- Premiação dos melhores leitores de cada turno - 2001/2004

- Palestra sobre a importância da leitura na sociedade - 2003/2004

- Oficina de interpretação: prática de jogos teatrais que proporcionem a desenvoltura e a sociabilidade, recursos lúdicos aplicados à dramaturgia $2003 / 2004$

Com a execução do projeto Minutos de Leitura proporcionamos aos usuários da BDGF a possibilidade de ser leitor, de entender e ampliar a compreensão do mundo, e estar em relação com o eu/outro. Ou seja, é poder ler-se no outro que está no texto que, às vezes, é diferente e outras, igual (CAVALCANTE, 1999).

\subsection{Premiação dos Melhores leitores}

Para incentivar a leitura e ao mesmo tempo o uso da biblioteca, a BDGF criou o prêmio Melhor leitor, onde são premiados o melhor de cada turno na SACEM (Semana de Artes do Colégio Estadual Manoel Vilaverde).

Os alunos que mais utilizaram a biblioteca e o seu acervo durante o ano - para leituras e pesquisas - fazem a publicidade do livro que mais gostou, com isto detectamos que nossos leitores não são apenas consumidores, são também produtores de textos. Os textos produzidos são afixados no mural da biblioteca funcionando como incentivo para outros leitores. 


\subsection{Aulas na biblioteca}

Para Simão, Schercher e Neves (1993, p. 15) “ativar a biblioteca escolar significa tornála um local ativo, dinâmico e ao mesmo tempo acolhedor a todas as propostas que visem o crescente entrosamento usuário-biblioteca". A BDGF pondo em prática o pensamento das autoras citadas anteriormente, realiza semanalmente o agendamento de aulas na biblioteca com objetivo de aproximar o aluno do conhecimento, facilitando projetos interdisciplinares. Esta ação evita colocar a biblioteca como um instrumento distante, estranho e até desconhecido à vida do aluno. Pois acreditamos que uma biblioteca escolar tem que ser organizada para se integrar à sala de aula, no desenvolvimento do currículo escolar.

\subsection{Exposições}

As exposições constituem um forte atrativo para o público. Nossa equipe atua nesse espaço sugerindo temas, organizando e, principalmente criando um lugar bastante agradável. As exposições mais freqüentes são de obras de arte produzidas pelos próprios alunos nas aulas de Arte. E ainda, exposição de livros por temas, por autores, por preferências dos alunos (os livros mais lidos do mês) e novas aquisições.

\subsection{Biblioteca no recreio}

O charme da BDGF tem conquistado os alunos com todos os recursos-mobiliário, ambiental e principalmente bibliográfico (jornais, revistas, gibis e livros de curiosidades) e também pelo calor humano. Prova disso é a declaração do aluno Edgar Antônio Mota do $3^{\circ}$ ano do ensino médio (2004): “A biblioteca é nosso "point" na hora do recreio". Não só Edgar, mas a maioria dos alunos do CEM compartilham essa mesma idéia.

3.8 Projeto Pró-melhoria dos recursos pedagógicos do CEM envolvendo diretamente a Biblioteca 


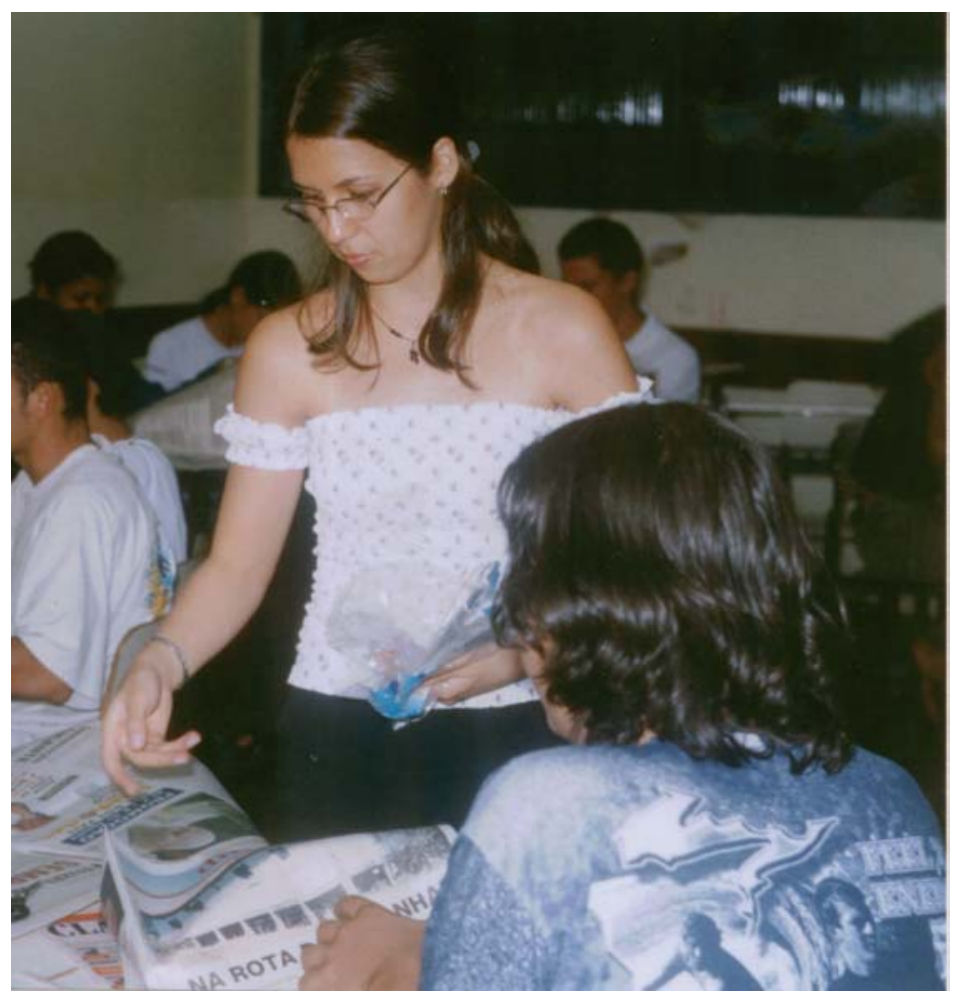

Equipe do Jornal CEMsura - Oficina de produção de textos jornalísticos em comemoração dos 2 anos de criação do jornal (junho/2004).

A BDGF preocupada com a ausência dos alunos na biblioteca buscou parceria com o Grêmio Estudantil no sentido de criar um jornal escolar. Acreditando na idéia, o Grêmio designou um dos seus membros para fazer parte do projeto com intuito de registrar as notícias sobre o que acontece dentro e fora do ambiente escolar.

Apoiados na idéia do jornal escolar proposto pelo francês Célestin Freinet (CAVALCANTE, 1999), na década de 20, e por Harris e Harris (1994), a BDGF passa a publicar em 2002 seu jornal.

Com a veiculação do jornal foi possível disseminar melhor os materiais disponíveis na biblioteca e promover maior interatividade entre biblioteca, professor e aluno. E, ao mesmo tempo, objetivamos sensibilizar os usuários pela causa da biblioteca, implicitamente, a pesquisa e a leitura. Para desenvolvê-lo, a BDGF convidou corpo discente, docente e administrativo para reescreverem suas leituras, as ações do colégio e da comunidade em forma de textos jornalísticos.

Primeiramente, constituímos um Conselho Editorial formado por alunos, professores e membros da biblioteca para coordenar o jornal. Em seguida, realizamos uma pesquisa 
para a escolha do nome do jornal. Esta fase foi bastante interessante, onde os alunos criaram diversos títulos justificando seu nome. O título eleito foi CEMsura que tinha por formação a aglutinação da sigla do colégio CEM mais a palavra censura. Que juntas formariam CEMsura, com a intenção de significado SEM CENSURA.

Escolhido o título para o jornal passamos a fase de promoção de oficinas para produção de textos jornalísticos, trabalhando com os alunos quais seriam as partes de um jornal. Em seguida, cada aluno produziria suas matérias para serem publicadas no jornal da escola. Não só as matérias produzidas nas oficinas seriam publicadas, mas também os textos selecionados pelos professores em sala de aula, recadinhos colhidos no recreio, informes de eventos e reportagem produzidas pelos professores e direção. A arte final do jornal coube ao talento de alguns alunos que tinham domínio de informática, sob a coordenação da BDGF. A distribuição do jornal era realizada de forma estratégica, somente recebia o exemplar quem levasse um livro literário para ler em casa, como forma de incentivo à leitura. Quando demorava sair a próxima edição, a cobrança era grande, pois os alunos ficavam eufóricos para ver sua matéria circulando.

Na tiragem do jornal CEMsura (Ano 3, abr. 2004) fez-se uma enquete a respeito do gosto dos alunos(as) a respeito dos seguintes pontos: professorado, exercícios (atividades em classe e extra classe), eventos escolares, colegas dos alunos(as), momentos recreativos, o uso dos serviços da biblioteca, da direção da escola, funcionários administrativos, aulas ministradas no geral e coordenação. Com a realização da enquete não objetivamos descaracterizar umas atividades profissionais em detrimento de outras - só objetivamos um momento para vermos o que os alunos pensam a respeito dos tópicos acima mencionados.

Para nossa surpresa a Biblioteca foi o local de preferência dos alunos(as), conforme o resultado da enquete. Com a experiência e vivência adquiridas no dia-a-dia, podemos deduzir que tal preferência está vinculada à possibilidade de uma comunicação mais íntima ${ }^{1}$ com os colegas; onde os mesmos podem dizer (dialogar) sobre assuntos proibidos ou seja, diálogos considerados de menor importância. Tanto é verdade que os

\footnotetext{
${ }^{1}$ Com a palavra íntima, nos referimos a uma conversa mais solta, sem nenhuma cobrança - onde os mesmos podem entrar em contato na comunicação dos iguais (adolescentes).
} 
três primeiros tópicos de preferência dos alunos(as) foram: Biblioteca (13,49\%), Colegas (13,17\%) e Recreio (12,45\%).

Não adianta reprimir nem a nós mesmos e tão pouco ao outro, quando agimos com repressão, produzimos relacionamentos ante-naturais, artificiais - não queremos pregar um abandono ao racionalismo, ao intelectualismo - queremos apenas dar um sinal para a urgência do sentir o outro que é parte de nós mesmos. Temos como exemplo, o computador, a televisão, o carro, motocicleta, etc., são objetos técnicos sem vida, sem coração - não podemos ficar subordinados ao tecnicismo da era moderna.

Graças à participação dos leitores do CEMsura, a BDGF conseguiu realizar dois anos de edição, com empenho, dificuldades, lutas, ideais e, felizmente, vitórias! Acalentados pelo sonho de que o jornal CEMsura fizesse parte do universo de leitura de todos do CEM demos continuidade ao projeto. Pois qualquer veículo de comunicação que tenta valorizar a escrita dos alunos dentro da escola, é um meio de avaliar e incentivar os alunos a se aprimorarem cada vez mais no mundo da escrita e da leitura.

\section{CONCLUSÃO}

Ser dinâmico, inovador e capaz de desenvolver ações que motivem alunos e professores a visitar e utilizar os recursos da biblioteca foi a nossa meta durante os anos de 2001 a 2004. As atividades realizadas pela biblioteca estão voltadas não só para a leitura do livro, mas também de mundo (FREIRE, 1994). Temos nos convencido a cada momento que através das atividades de leitura podemos propiciar ao cidadão uma visão abrangente da sua realidade, que a criatividade e cidadania cultural estão sempre presentes.

Não medimos esforços para tornar o ato de ler algo interessante, prazeroso. Organizamos eventos dentro do calendário regular capazes de dar visibilidade necessária à política de incentivo à leitura e pesquisa, garantindo a todos o acesso aos saberes necessários à formação do usuário na utilização da biblioteca. 
Assim como Grandi (2002), acreditamos que a transformação da escola frente à sociedade do conhecimento passa, sobretudo pela atuação da biblioteca escolar e por suas práticas informativas e educativas contextualizadas no projeto pedagógico para não somente transmitir informação, mas também gerar uma atividade cognitiva.

Estou ciente da importância da biblioteca no contexto escolar e do trabalho inovador que devo exercer como dinamizadora da biblioteca escolar, contribuindo para o crescimento pessoal e intelectual dos alunos, enriquecendo a prática docente, e integração da comunidade escolar, para a melhoria da qualidade do ensino. Para que o processo de leitura dos alunos no contexto da biblioteca não tenha uma pseudoleitura, um empreendimento mecânico - termos utilizados por Silva (1997) - é que a BDGF propôs desenvolver atividades de leitura que levassem a compreensão e recriação de suas ações.

Concluímos que a BDGF foi bastante dinâmica durante o período de 2001 a 2004, pois suas ações contribuíram e fortaleceram o interesse dos usuários pela leitura. Criaram-se várias oportunidades para o desenvolvimento crítico, pessoal e coletivo, estimulando a imaginação e a capacidade criadora dos alunos. Enfim, os objetivos da BDGF foram ao encontro com os da Fundação Nacional do Livro Infantil e Juvenil (Brasil, 2002) que são os mesmos anteriormente relacionados.

\section{REFERÊNCIAS}

CAVALCANTE, Joana. O jornal como proposta pedagógica. São Paulo: Paulus, 1999.

FREIRE, Paulo. A importância do ato de ler: em três artigos que se completam. 29. ed. São Paulo Cortez, 1994.

FUNDAÇÃO NACIONAL DO LIVRO INFANTIL E JUVENIL (Brasil). Biblioteca da escola: direito de ler. Rio de Janeiro: Fundação biblioteca Nacional; Proler, 2002.

GRANDI, Sonia Maria. Biblioteca escolar e seu papel na era da informação. Pátio, Porto Alegre, v. 6, n. 21, maio/jul. 2002.

HARRIS, Ray; HARRIS, Chris. Faça seu próprio jornal. 3. ed. São Paulo: Papirus, 1994. 
INHUMAS. Colégio Estadual Manoel Vilaverde. Plano de Desenvolvimento da Escola. Inhumas: [s.n.], 2003.

MARTINEZ, Lucila; CALVI, Gian. Biblioteca e escola criativa: estratégias para uma gerência renovadora... Petrópolis: Autores \& Agentes \& Associados, 1994.

MARTINS, Helena. O que é leitura. São Paulo: Brasiliense, 1994. (Primeiros passos, 74).

SILVA, Ezequiel Theodoro da. Leitura e realidade brasileira. 5. ed. Porto Alegre: Mercado Aberto, 1997.

SIMÃO, Maria Antonieta Rodrigues; SCHERCHER, Eroni Ker; NEVES, Iara Conceição Bitencout. Ativando a biblioteca escolar: recursos visuais para implementar a interação biblioteca-usuário. Porto Alegre: Sagra-DC Luzzatto, 1993. 


\section{Maria Aparecida Rodrigues de Souza}

Bacharel em Biblioteconomia pela Universidade Federal de Goiás e bibliotecária responsável pela Biblioteca Domingos Garcia Filho do Colégio Estadual Manoel Vilaverde, desde 1997 a abril/2004, em Inhumas - GO. fone: (62)511-2403

e-mail: cirosou@bol.com.br

\section{Agradecimentos}

Este trabalho contou com a leitura atenta e os comentários de Rita Rodrigues Souza, Gaspar Cândido Ferreira e Luzia Felizardo, a quem muito agradecemos. É claro que elas não partilham da responsabilidade do conteúdo relatado.

Relato de Experiência aceito para publicação em: 07/ 2005 